Article

\title{
On-Board Wind Scatterometry
}

\author{
Xingou $\mathrm{Xu}^{1, * \mathbb{C}}$, Xiaolong Dong ${ }^{1,2}$ a and $\mathrm{Yu} \mathrm{Xie}^{3} \mathbb{C}$ \\ 1 Key Laboratory of Microwave Remote Sensing, National Space Science Center, Chinese Academy of \\ Sciences, Beijing 100190, China; dongxiaolong@mirslab.cn \\ 2 The University of Chinese Academy of Sciences, Beijing 100864, China \\ 3 Beijing Institute of Technology, Beijing 10081, China; xieyu1993@bit.edu.cn \\ * Correspondence: xuxingou@mirslab.cn; Tel.: +86-10-6255-0409
}

Received: 4 March 2020; Accepted: 7 April 2020; Published: 9 April 2020

check for updates

\begin{abstract}
Real-time (RT) ocean surface wind can make key improvements to disaster alarmingand safety of maritime navigation to avoid loss in property and human lives. Wind scatterometry is a well-acquainted way of obtaining good quality ocean surface winds, and it has been in application for decades. Existing wind-obtaining chains employ ground stations for receiving observations and can, at best, provide products in around 30 minutes for limited regions. In recent years, a satellite information-obtaining and transmission network is the new trend of Earth observation. In this research, on-board wind retrieval environment and procedures, which are different from traditional wind-obtaining chains, are proposed. First, the establishment of the on-board environment is instructed. Structures of each module are provided. The ground simulation system is been established based on this. After that, existing observing and processing routines of wind scatterometry are described, and then an on-board processing chain proposed and described. Modifications to existing satellite-ground chains are highlighted. The proposed method is validated in Level 0 data from the Chinese-French Oceanic SATellite (CFOSAT). Experiments indicate that the proposed on-board processing procedure can provide comparable results to ground-processed wind products. The root-mean-square error (RMSE) of wind speed for a track of data used in the experiment was about $0.26 \mathrm{~m} / \mathrm{s}$, and it was about $0.8^{\circ}$ for wind direction. By decreasing wind field result quality, calculation time can be lessened in the on-board environment. However, it is found that in the whole chain of on-board wind generation, the most time-consuming procedure is observation-obtaining. The proposed on-board processing method can achieve good wind accuracy while meeting RT applications with good processing time. This provides a good complement to existing on-board-observing-ground-processing chains for RT applications.
\end{abstract}

Keywords: on-board processing; wind scatterometry; real-time

\section{Introduction}

Ocean surface wind fields are paramount parameters in applications such as disaster monitoring, prediction, and sailing routine optimization [1]. They are also vital in oceanography and global climate research [2]. Remote sensing is the only effective way to obtain ocean surface winds, (synthetic aperture radar (SAR) is well-applied for coastal winds $[3,4])$, and scatterometers are capable of continuous observations in much larger coverage. They are well-considered as the most suitable instrument capable of retrieving ocean surface winds. There are long-term improved and validated geophysical modelling functions (GMFs) [5] that map scatterometer observations to wind fields. Additionally, the stability shown in scatterometer calibration leads to a high accuracy in wind retrieval [6-10]. Scatterometer winds have already made great contributions to improvements to numerical weather prediction (NWP) models, such as in the European Centre for Medium-Range Weather Forecasts (ECMWF) [11]. 
Scatterometers at work in space today include Advanced Scatterometer (ASCAT) -A, B, and C onboard Meteorological Operational satellite program (MetOp) series [12], the scatterometer onboard the Chinese-French Oceanic SATellite (CFOSAT), i.e. CFOSCAT [13], the scatterometers onboard Hai Yang-2 (HY-2)-A and B Satellites, i.e. HSCAT -A and B [14], and Oceansat-2 Scatterometer (OSCAT-2) onboard Scatterometer Satellite (ScatSAT) [15]. A dual-frequency scatterometer onboard the Feng Yun-3 (FY-3) Satellite is scheduled by the end of this year; it will be a good recruit to the scatterometer family [16]. Operational data processing procedures and systems for these spaceborne scatterometers have been well-established, being important parts in the applications listed above [17-19].

The traditional spaceborne scatterometer application chain starts from observations conducted by sensors, follows by signal detection, simple on-board signal processing, and relevant information generation. If necessary, all of those data are then compressed and downlinked with auxiliary data. Auxiliary data include satellite orientation and positioning information. These data form level 0 (L0) data when collected by ground stations. Higher levels of processing procedures that give products of wind fields are generally carried out after L0 data are distributed to processing agencies. Application institutes obtain higher levels of products via ground networks from them. State-of-the-art processing, transforming routines, and application modes have been developed to take advantage of well-located ground stations and networks. They are fast and stable. Advanced Retransmission Service (EARS) conducted by the European Organisation for the Exploitation of Meteorological Satellites (EUMETSAT) is a good example of networks of advanced high resolution picture transmission (AHRPT) reception stations. The wind products from EARS can be provided to end-users within $30 \mathrm{~min}$ (min) after observation [20]. However, similar application chains can only meet regional coverage. For far open ocean regions that ground stations cannot reach, support information is unable to be provided without extra support from communication satellites, and $30 \mathrm{~min}$ is longer than many small scale events that can be observed by scatterometers but are difficult to be predicted by NWP, e.g., convections in the tropical region [21]. The real-time (RT) information of such events is useful for applications like disaster alarms for ships and airlines.

With the fast development of satellite remote sensing methods, on-board hardware types and capabilities, an innovative application mode involving generating and distributing higher levels of products with extracted information rather than original observations has come out [22,23]. Current applications concentrate on on-board feature extraction to relieve transmissions of large amounts of observations from sensors, such as SAR and optical cameras [24,25]. The advent of micro-nano satellites, accompanying burst developments of neural network hardware components, has propelled this processing mode to the experimental stage with affirmative results [26]. The new generation of communication satellites has provided the possibility of a data downlink routine for RT transportation, as well as the possibility of solving downlink obstacles for on-board processing for countries who lack suitable ground station sites $[27,28]$.

Off-line ground processing chains of scatterometer data are already well-established. If integrated to an established on-board environment, the RT processing and direct broadcast of retrieved winds with high accuracy can be realized for RT applications with a communication-remote-sensing mode [29,30]. This research demonstrates the whole procedure. An on-board processing environment is simulated with processors and systems that can be applied to satellites. Steps of traditional processing are modified for the on-board environment and RT processing requirements. Validation is achieved with application to CFOSCAT real data. First, the on-board environment is established, and reasons for its applicability to the spaceborne environment are provided. The method to distribute processed results, such as on-board wind products are also presented. Then scatterometer processes that are adjusted for on-board applications, including procedures from return power to wind product generation, are described with modifications to the proposed data product forms. Changes made to traditional procedures are described. After that, CFOSCAT data for the validation of the new processing chain and environment are introduced, followed by experiment results. Differences in accuracy with the traditional off-line processing chain are provided. For the validated on-board processing chain 
especially, the relationship bewteen accuracy and processing time changes due to the information involved in processing is analyzed and provided. It is concluded that on-board scatterometer winds can be realized with the accuracies needed to meet application requirements. This can be achieved as an extra parallel working mode of existing scatterometers, complementing their wind producing chains. This research is the first discussion on on-board wind scatterometry for satellites. The proposed method can fill the blank of stable far sea RT winds in future scatterometer missions. This can benefit sailing routing optimizing systems, especially for scientific research ships that go into rare regions of oceans. Conclusions can also be valuable as part of future intelligent observation systems in terms of locating possible disaster regions with RT winds in order to give alarms and for further highlight monitoring. The proposed method's RT capability also provides well-established inputs for future NWP application schemes described in [31] and contributes to improving short-term forecasts.

\section{The On-Board Processing Environment and System}

The space-borne scatterometer is an implementation of real aperture radar, with capability of obtaining better accuracy and precision of the received power measurement [32]. These scatterometers transmit and receive the backscattered signals from the ocean surface. Received signals are detected and processed as digitalized power values, together with noise measurements and auxiliary data describing observing geometry and polarization; they are then transferred to ground stations $[33,34]$. Wind products are obtained with computers distributed in institutes or agencies before being provided to application end-users. The proposed on-board environment integrates traditional observing and ground processing chains for wind products. Figure 1 illustrates both routines.

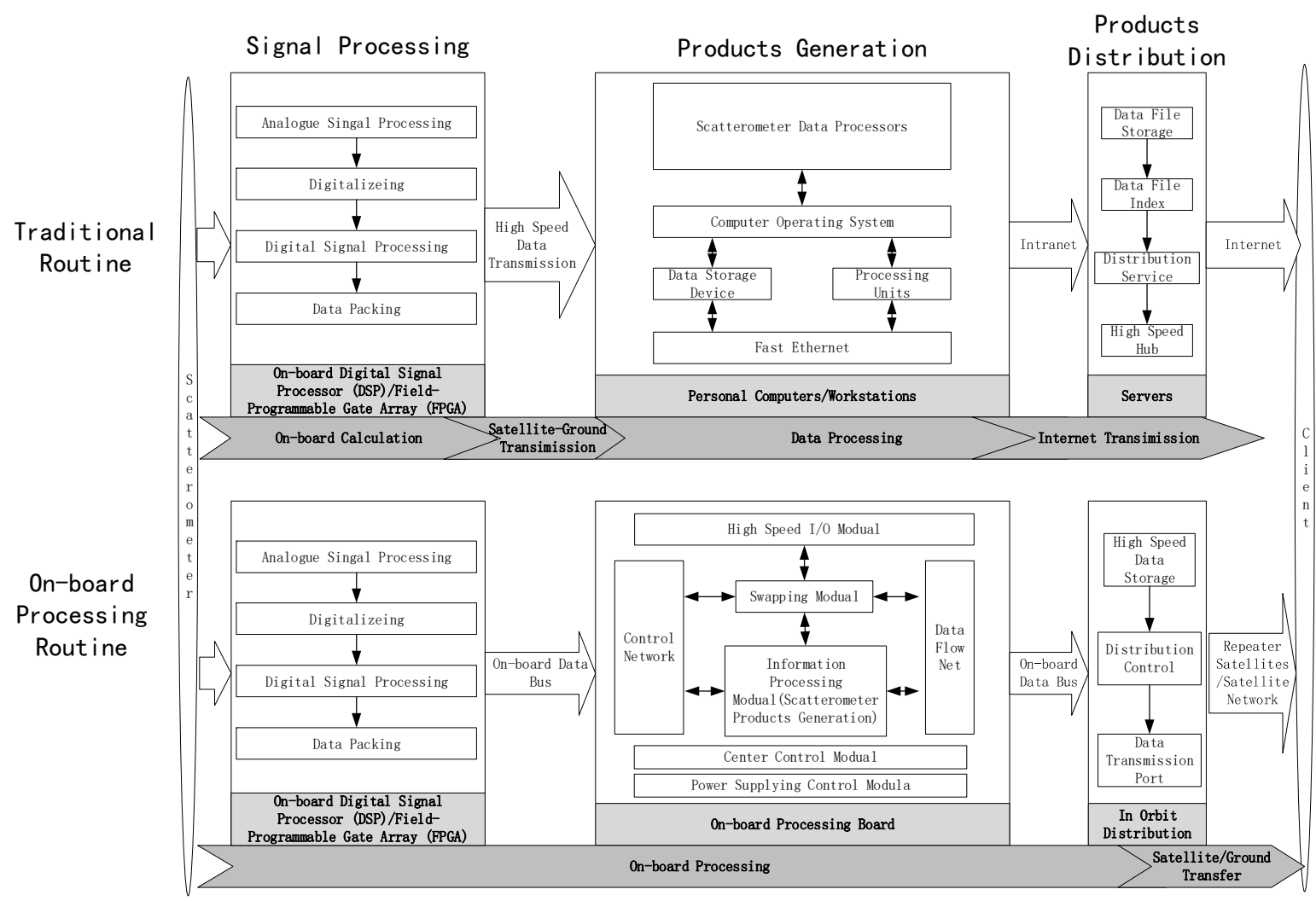

Figure 1. Comparison of traditional and the proposed on-board processing routines.

Processing modules and hardware implementations are also shown in Figure 1. The functions required for the on-board processing system can be realized from the control system, data processing, high-speed input-output (I/O), data storing, and swapping modules. The control module receives and interprets orders to specific tasks and sends them to other modules. The I/O module provides 
data interchange channels capable of meeting the speed of data observing and product generating. The swapping module manages data transmission flows between modules and processors within a module. These modules form the on-board processing environment. Digital signal processor (DSP), a field-programmable gate array (FPGA), and an embedded graphics processing unit (GPU) can be used to implement these modules. On an FPGA mother-board, together with two sets of Double-Data-Rate of version 3 (DDR3) Random Access Memory (RAM), FPGA chips realize I/O and control procedures. Data compression before transmission can also be done. Since the wind scatterometry requires multi-inputs and iterations in wind retrieval procedure, embedded GPUs or DSP are suitable choices to meet its requirements. In this research, an embedded Jetson TX2 GPU [35] was adopted for its better calculating ability and flexibility in applications. Together with FPGA chips that swap data with the GPU and the I/O module, the processing module was complemented, as illustrated in the middle part of Figure 2. Based on these settings, a specific on-board processor (SOBP) was designed and developed. The hardware scale of this SOBP is shown in Table 1. Its parameters indicate that it is suitable for satellite applications [36]. Results obtained on-board are downlinked in communication channels provided by communication satellites and broadband low Earth orbit (LEO) satellites [37]. For the validation of the on-board-scatterometer wind product generation algorithms proposed in this research, the simulation of the on-board environment was necessary. Figure 2 illustrates a simulated environment where the SOBP has the same set of parameters as described above. Differences with the actual on-board environment are for data input and product output only. Measurements with simultaneous auxiliary attributes of observations are provided by a personal computer (PC), while the result products are output to another instead of being downlinked for RT applications.

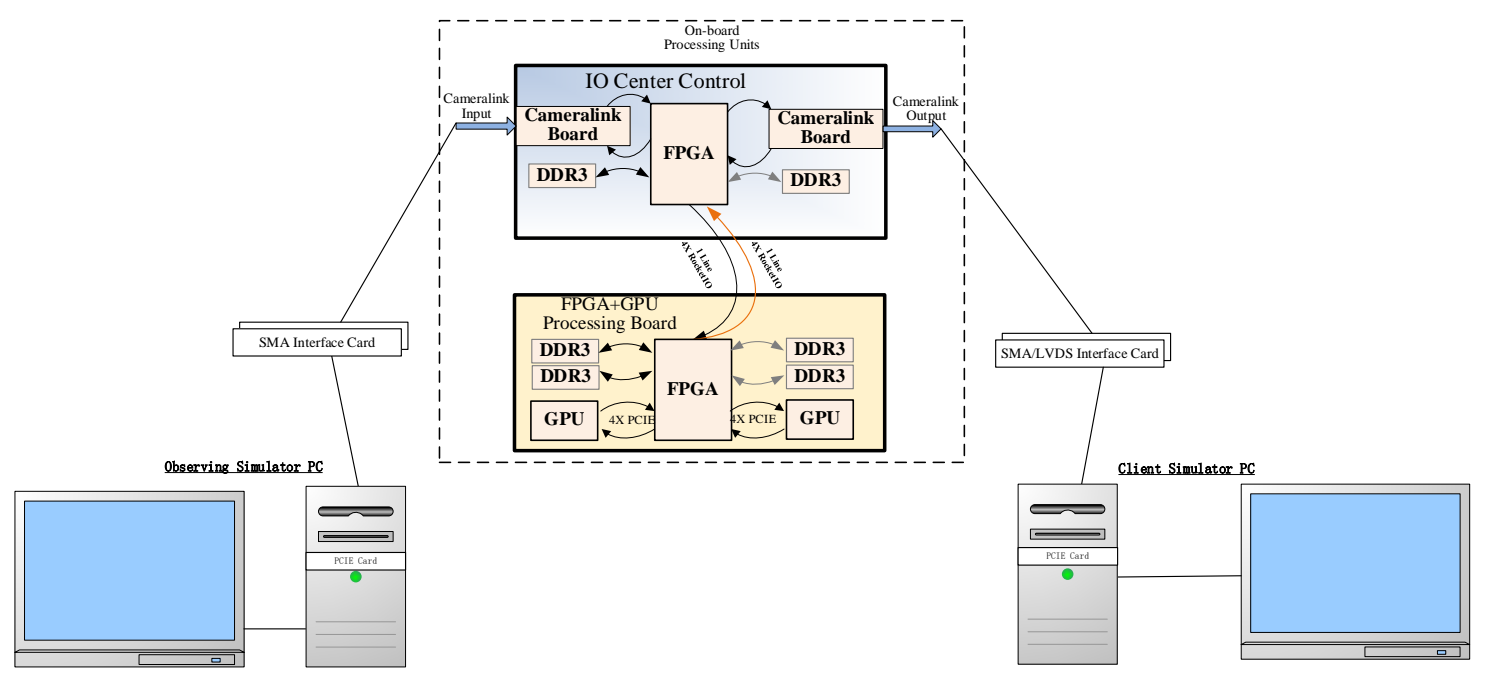

Figure 2. Illustration of system simulating the on-board environment and processing routine for method validation.

Table 1. Hardware scale of the specific on-board processor (SOBP).

\begin{tabular}{cc}
\hline Indexes & \\
\hline Weight & $15 \mathrm{~kg}$ \\
Size & $425 \times 254 \times 240 \mathrm{~mm}$ \\
Power & $280 \mathrm{~W}$ \\
Temperature & $50^{\circ} \mathrm{C}$ \\
\hline
\end{tabular}

\section{Wind Scatterometery Processing Chain and On-Board Processing Modifications}

The well-developed off-line ground-based processing is composed of pre-processing and wind inversion [34]. During pre-processing, noises in observations are subtracted and effects due to observing geometry and antenna pattern are eliminated before normalized radar cross sections 
(NRCS) are calculated. In wind inversion, NRCS obtained within a wind retrieving unit, i.e., a wind vector cell (WVC), are grouped. A WVC is usually a square on the ocean surface. With a GMF, the wind field is inverted for each WVC by using the maximum likelihood estimation (MLE) method. GMFs are semi-empirical models that map NRCS to winds of the ocean surface, considering their observing geometry from scatterometers operating in different frequencies and polarizations. The whole procedure of on-board scatterometer data processing inherits procedures from this chain, with specific procedures and NRCS and wind products being formation modified to provide RT products. In this section, differences in product formation are first described for on-board procedures, followed by modified algorithms in processors generating them.

\subsection{Modifications for On-Board Products}

Traditional scatterometer products are labeled by different levels. Level 0 (L0) data are segmented measurements that are produced at ground stations with data downlinked from satellites. When the effects of antenna pattern and observing geometry are eliminated, NRCS can be derived. With auxiliary information, including observing geometry and polarization, Level 1 (L1) products can be assembled. Wind fields are Level 2 (L2) products. L2 winds are retrieved from in L1 NRCS that are grouped within WVCs [34]. Higher levels of data are also developed for further steps of research and applications [38]. Different processors are applied to generate different levels of products [39].

To meet RT applications, L2 and lower level products are directly provided from an on-board processing routine. Data components and processor functions are the same as traditional procedures. However, to achieve RT ability, modifications are made. Since an on-board processing routine is used for RT applications and is complementary to existing wind scatterometry, generally, only an L2 on-board product is required for downlinking. L0 and L1 products, which are less application-oriented, can be obtained from the ground processing chain. For on-board L1 processing, due to the omission of a signal transferring procedure, packing auxiliary data into products is not necessary; only the labeling of them with corresponding observations is required. Obtained signals and auxiliary information are directly provided to the on-board L1 processor. Except for algorithm modifications, observations distributed in a WVC are identified and gathered as inputs to the L2 processor for wind retrieval. Wind inversion is immediately conducted when NRCS in a WVC are obtained. Though data structure and information are the same, the size of on-board L2 product is much smaller than that of the ground products. This is due to a much shorter period of observation for RT applications. The specific amount of data differs for different types of scatterometers [12,14].

\subsection{The On-Board Pre-Processing}

A scatterometer pre-processing procedure is implemented by the L1 processor. It generates L1 NRCS from L0 data. In traditional L0 processing steps, when noise that is simultaneously obtained with observations has been subtracted, the signal-to-noise ratio (SNR) can be calculated [34]. Following this comes a key step for pre-processing, i.e., eliminating observing geometry and antenna pattern effects. Generally, frequency modulation for each pulse is adopted for the enhancement of resolution, and different frequencies of return signals measured from the scatterometer are mapped to different ground distances. In a pulse, fast Fourier transform (FFT) bins can be divided into different slices. The number of slices is determined by beam width [40,41]. Doppler effects in frequency (Doppler frequency) are due to Earth's rotation and sensor speed relative to Earth's surface. When the Doppler frequency, center frequency shift, and frequency modulation slope of the signals are compensated for, the frequencies of a slice can be mapped to different slant range distances. Combinations of FFT bins of a return pulse into slices are achieved before forming L0 data in order to make sure each slice has the same ground coverage. In this procedure, the bin grouping is achieved with a look-up table (LUT) that provides an estimated Doppler frequency. This LUT is calculated according to predicted positions of scatterometer in its orbit. When an observation is conducted, differences of the true Doppler frequency with this LUT are estimated and compensated for in the L1 processor by considering the observing 
position. Together with antenna orientation, a slice location on the ocean's surface and a corresponding antenna gain factor can be obtained. The factor that embodies the antenna gain effect with a specific geometry in observation is referred to as the calibration factor, namely the X-factor. When the value of signal power of a slice is divided by the X-factor, NRCS can be calculated. Then, their standard deviations $\left(\mathrm{K}_{\mathrm{p}}\right)$ can be calculated when the NRCS of all slices are determined [34]. The whole procedure is shown in Figure 3a. The core algorithm is bordered by the dashed rectangle. It is used to calculate the discretized integrating for the X-factor in Equation (1) [40]:

$$
\begin{array}{r}
X=\frac{C^{2}}{T_{p}} \sum_{k=k_{s}}^{k_{e}} \sum_{i \in \mathcal{F}}\left(\frac{\delta A_{i} g_{i}\left(t_{\text {trs }}\right) g_{g_{i}}\left(t_{\text {rec }}\right)}{r_{i}^{4}}\right) \\
\left.|| \sum_{n=n_{s, i}}^{n_{s, i}+N_{p, i}} \exp \left\{2 \pi j\left(f_{b, i} T-\frac{k}{N}\right) n\right\}\right|^{2}
\end{array}
$$

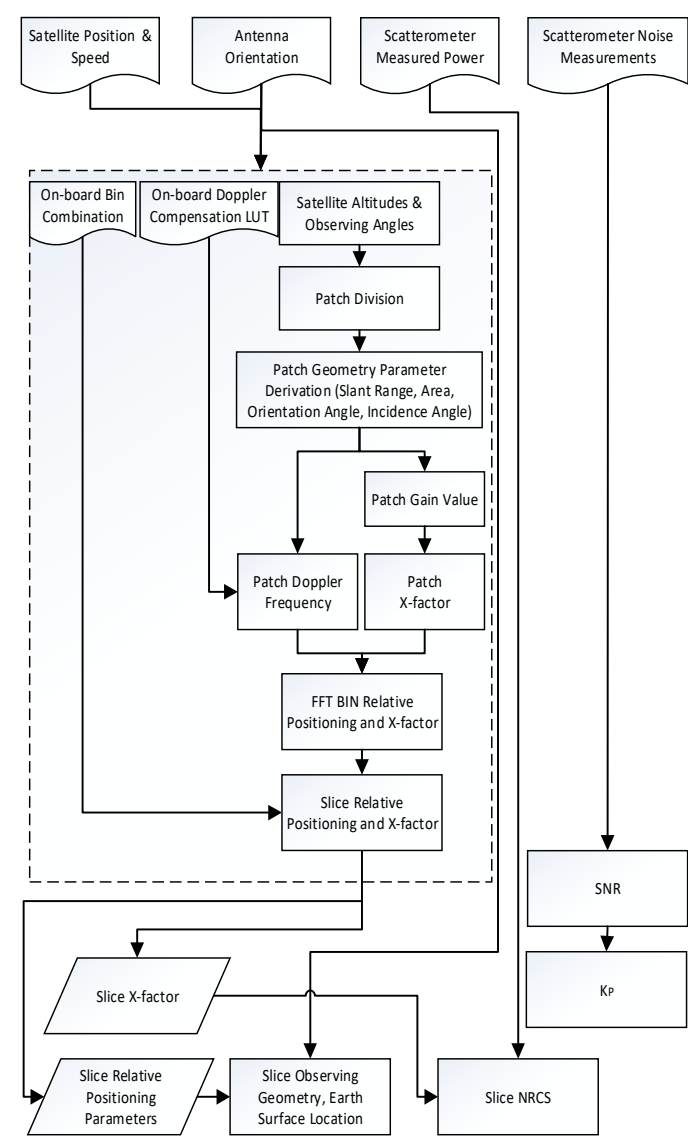

(a)

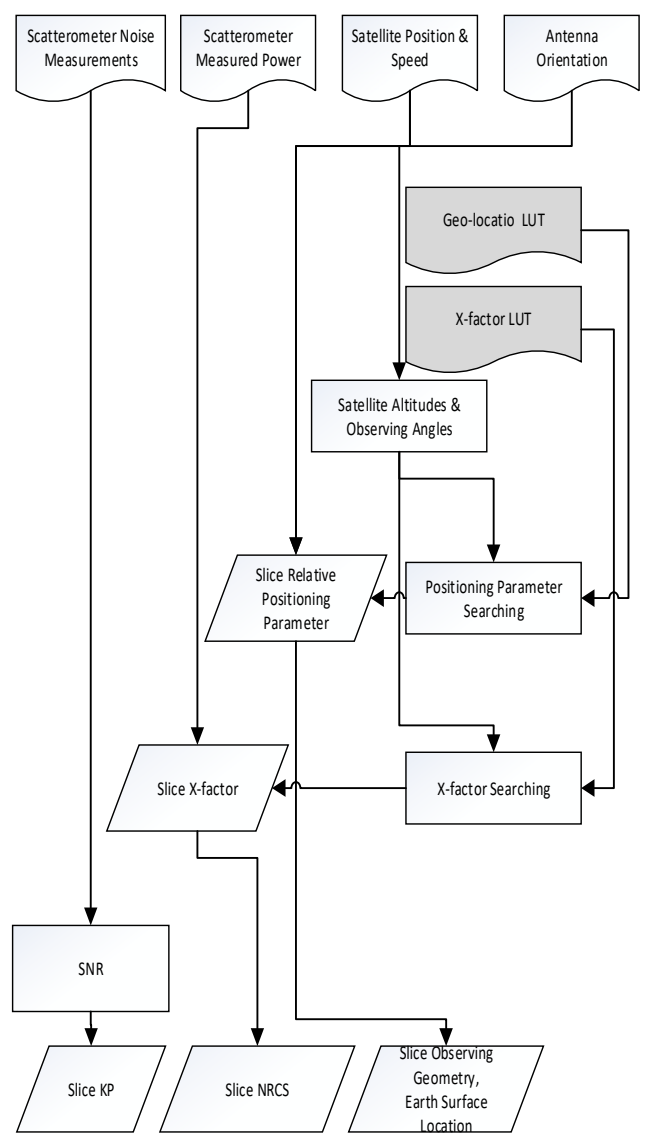

(b)

Figure 3. Traditional pre-processing routine (a) and on-board procedures with newly included look-up tables (LUTs) (b).

In Equation (1), the X-factor is written as X. C represents constants related to routine insert loss. The insert loss related temperature is $T_{p} . k_{s}$ and $k_{e}$ are the start and end FFT bin numbers in a slice, respectively. $F$ represents the observing region, which is composed by $i$ small patches on the Earth's surface, to realized the discretized summary in Equation (1). There are $N$ samples of small patches in a pulse. This number is determined by observing the window time $T$. $f_{b, i}$ is the center frequency of the $i$ th patch. During $T$, a small patch gives a return signal that may affect different bins. $A$ and $g$ are the area and gain of the $i$ th patch. $N_{p, i}$ represents the number of small patches captured in the observation time of a slice. $n_{s, i}$ is the start patch. [40]. In Figure 3a,b, the determination of $X$ involves a 
geolocation procedure. First, position coordinates are expressed in satellite coordinate system (referred to as relative position in Figure 3), and then they transformed into the ground coordinate system, which is used more often in applications [40].

Figure $3 b$ shows the pre-processing for the on-board routine. Modifications made from traditional processing can be spotted by taking reference from Figure 3a. Key outputs from X-factor determination procedures are the locations and NRCS of the slices. In Figure 3b, in addition to the LUT used for Doppler effect correction employed in the traditional observing chain, two LUTs are proposed in this research to complete this procedure, i.e., the geolocation LUT and the X-factor LUT. They are calculated in advance according to the rectangle-lined region in Figure $3 \mathrm{a}$, considering all possible observing position, altitude, and antenna orientation parameters in discrete steps. Applications of these two LUTs can accelerate processing speed for RT applications. As shown in Figure 3b with satellite position, speed, and antenna observing orientation, the position of a slice relative to the satellite can be found from a geolocation LUT. With the same inputs, the X-factor can be found. Inputs for both LUTs are the latitude, the ascending/descending label, and the antenna azimuth angle. The steps for the construction of them are $0.085^{\circ}$ and $0.3^{\circ}$ of latitude and antenna azimuth angle, respectively. Considerations in balancing the calculating ability of on-board hardware and step sampling density for LUTs are provided after the experiment section.

\subsection{On-Board Wind Inversion}

When the NRCS of slices are obtained, the WVC they belong to is determined before wind field inversion. WVCs are divided according to their predicted satellite routine. A $25-\mathrm{km}$ sized grid is generally applied in wind products [34] and was adopted for this research. An LUT records WVC information that is then stored in an on-board storage device. This LUT is generated with predicted satellite and slice positions located on the Earth's surface. The inputs for searching WVCs with the NRCS of slices by using an LUT are satellite latitude, observing azimuthal angle, and track number. Output is the number of WVCs. When measurements are obtained on-board, the differences between the actural and the predicted observing geometry are generally less than a WVC lateral length. The differences are calculated; if they are not zero, the location of the slice is compared with the center of the WVC found from the LUT. If it is located outside the WVC, an adjacent WVC from the LUT is checked for this slice. Searching continues until the correct corresponding WVC number is obtained. Land and ocean marks of NRCS are also obtained during WVC locating.

Besides slices, particularly for rotating fan-beam scatterometers, view divisions are generally applied before wind inversion. A view includes slices with similar observing geometries, and it can be defined as slices in a WVC that are obtained in the same rotation of the antenna. The NRCS, geometry, and $\mathrm{Kp}$ of a view are obtained by averaging those values of slices within it. For fan-beam scatterometers, the NRCS of views within a WVC, instead of slices, are used as inputs for wind inversion.

The wind fields of a WVC can be inverted from GMFs in the MLE method. After MLE, the ambiguity removal step is required for the selection of wind directions as output results. In traditional wind inversion, circular medium filtering and two-dimensional variational ambiguity removal (2-DVAR) are optional methods [19,42]. In this procedure, background information from NWP is used. For on-board processing, the renewal of NWP information can be achieved in a future up-link routine [29,30]; for the simplicity of algorithms, in this research, circular medium filtering without NWP was used in wind direction inversion. The accuracy of this processing chain is evaluated in the following experiment section. Figure 4 illustrates the wind inversion steps developed in this research. To guarantee wind product generation speed, two steps were modified. First was in the MLE procedure; instead of the estimation of all solutions, the searching for maximum likelihood solution was divided into searching in coarse and finer steps. In general wind inversion, the searching step size is $0.2 \mathrm{~m} / \mathrm{s}$ and $5^{\circ}$ for wind speed and direction, respectively. The step for coarse searching in on-board wind inversion is $2 \mathrm{~m} / \mathrm{s}$ and $30^{\circ}$. Traditional step sizes are used for finer step searching. Second is that the GMF LUT used in 
on-board processing was interpolated into finer resolution. The resolution for incidence angle was $0.1^{\circ}$, the wind direction was $0.5^{\circ}$, and the wind speed was $0.1 \mathrm{~m} / \mathrm{s}$.

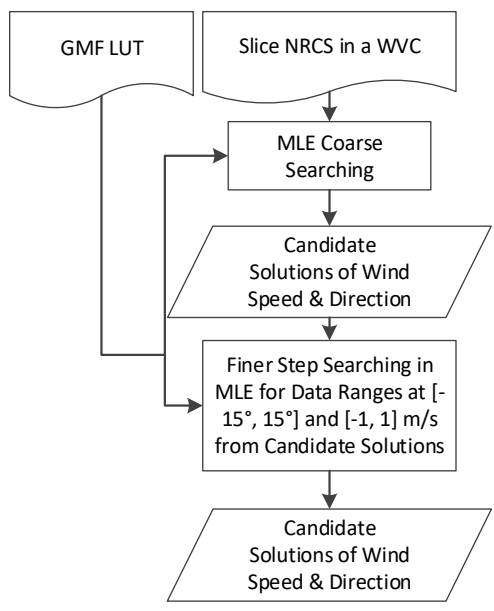

Figure 4. Wind inversion procedures of a wind vector cell (WVC) for on-board processing.

\section{Experiment and Results}

To validate the proposed method of on-board wind scatterometry, the on-board processing chain for scatterometer was established and simulated with the system illustrated in Figure 2. Then, CFOSCAT data were applied to this system.. The description of these data is in Section 4.1. The on-board L1 processing took the information of each pulse from L0 data obtained from the ground station as an input unit. In wind inversion, LUTs were calculated according to system design parameters and the rotating-fan-beam-antenna feature of CFOSCAT. Views were generated from slice NRCS for wind inversion. Neighboring WVCs were located for medium filtering in wind direction determination. The results of these processing steps are described in Section 4.2, with a validation of the proposed method.

\subsection{Data Description}

An L0 product from CFOSCAT that was received from the ground station was employed for the experiment to validate the proposed on-board processing method. CFOSCAT is the first rotating fan-beam scatterometer ever in space [43]. It was launched in October 2018 onboard CFOSAT. The data employed for this research were from 14th March 2019. Observations were obtained from 9:30 to 11:05, corresponding to a track of data received in the ground station. For the validation of the proposed method, accuracy evaluation was achieved by a comparison made with the ground-processed products [44].

\subsection{Results and Analysis}

In this part, L1 products from on-board preprocessing are displayed, and then on-board wind inversion with a full resolution of the LUTs described in Section 3. When apply theseLUTS, that more time is required in the proposed on-board processing chainis illustrated. The sesampling of LUTs to a half and a quarter number of samples LUTs for geo-locating and the X-factor were applied to obtain the LUTs of fewer samples. The resampled dimensions of the LUTs were latitude and antenna azimuth angles. Comparisons were made with the full and smaller sample of LUTs. Figure 5 illustrates the ground L1 product and the on-board NRCS distributions of the track of data used in the experiment. Figure 6 illustrates a randomly selected pulse from data in Figure 5. The horizontal axes of both figures are longitudes in degrees, the vertical axes are latitudes in degrees, and color indicates amplitudes of the NRCS in dB. In both figures, the (a) sections are from ground products, the (b) sections are from 
on-board procedures in full resolution LUTs, and the (c) and (d) sections are from on-board products obtained in half and a-quarter sample numbered LUTs, respectively. From Figure 6, the differences in geo-locating and NRCS amplitude derivation differences are not obvious, though the (d) sections in Figures 5 and 6 appear much noisier than the (a) and (b) groups. Taking the positions of L1 ground products as references, the root-mean-square error (RMSE) of the on-board results in the (b) of Figure 5 is $0.93 \mathrm{~m}$, and the half number of sampling LUT results in (c) is $2.81 \mathrm{~m}$, and $4.81 \mathrm{~m}$ for (d).

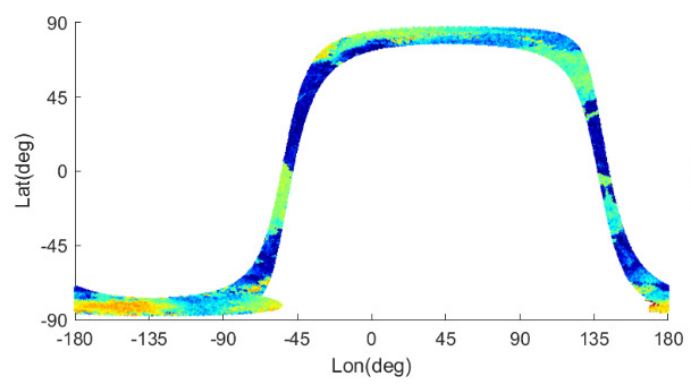

(a)

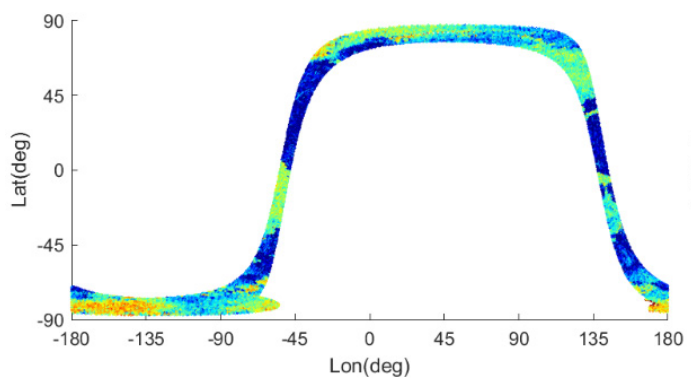

(c)

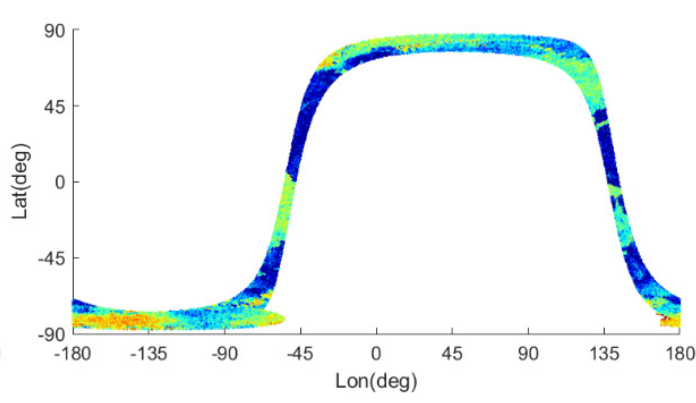

(b)

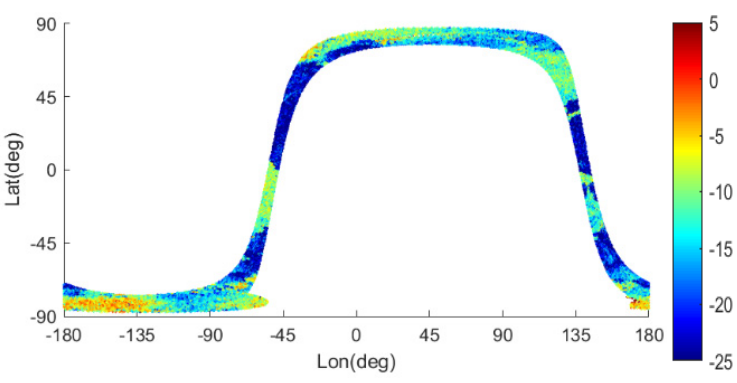

(d)

Figure 5. Ground level 1 (L1) product (a) and on-board normalized radar cross section (NRCS) distributions in LUTs for geolocating and X-factors in full resolution (b); half number resampled (c) and a quarter number resampled (d). Color indicates NRCS values in $\mathrm{dB}$.

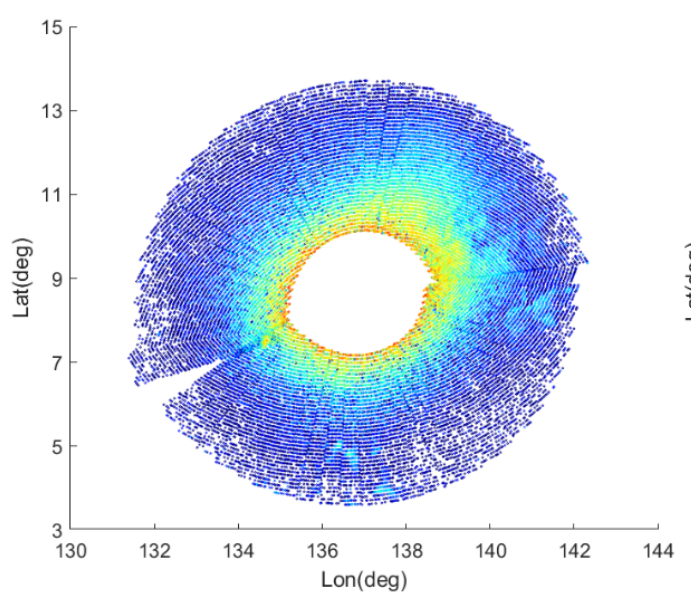

(a)

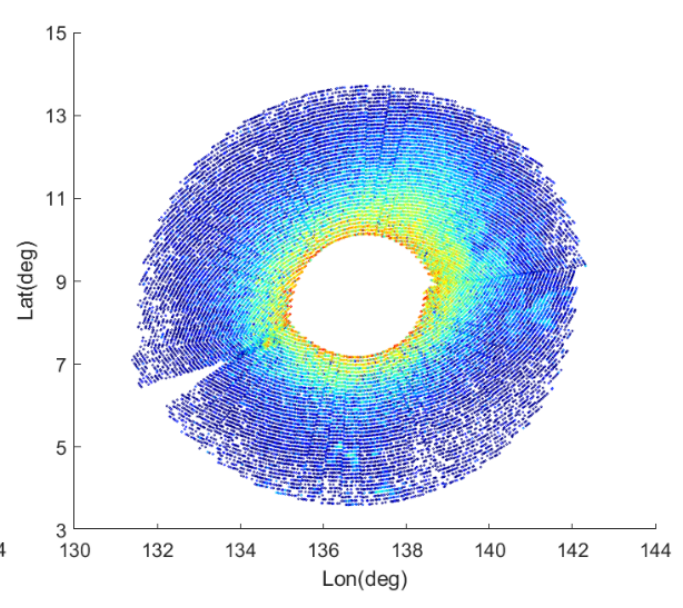

(b)

Figure 6. Cont. 


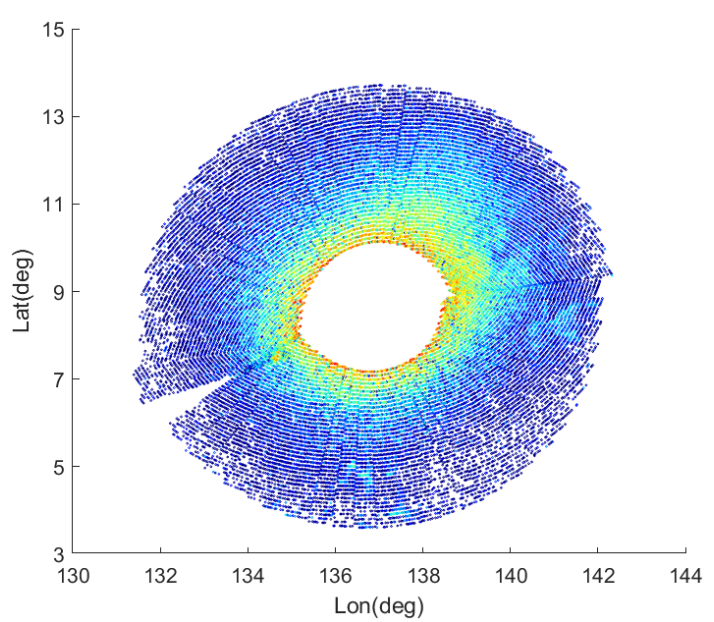

(c)

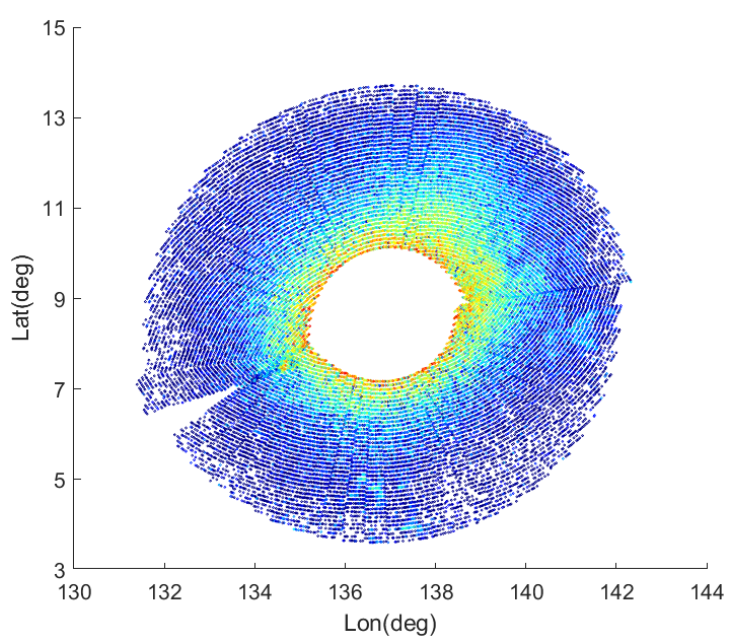

(d)

Figure 6. A randomly selected rotating circle of observations. (a)-(d) are labelled in the same order as Figure 5. Color indicates NRCS values in $\mathrm{dB}$ and is of the same scale of that in Figure 5.

Figure 7 shows correlations with error bars for the slice NRCS of ground and on-board products. The horizontal axis represents the NRCS from the ground L1 products, and the vertical axis represents the NRCS from on-board procedures. The color represents sample number density in dB. The on-board obtained NRCS in (a) are from LUTs in the original resolution, and those in (b) and (c) are in a half and a quarter number resampled LUTs. Specific values are listed in Table 2. It can be observed that when the on-board results were with large differences from ground products, the resampled LUTs also tended to give large differences. There was a similar trend in the standard deviations (stdev.). values. However, when the stdev. reaches largests or smallest values, it is not not necessarily that the corresponding differences in mean also reach the largest or the smallest values.

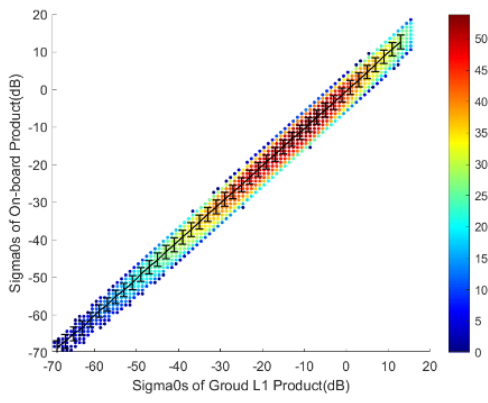

(a)

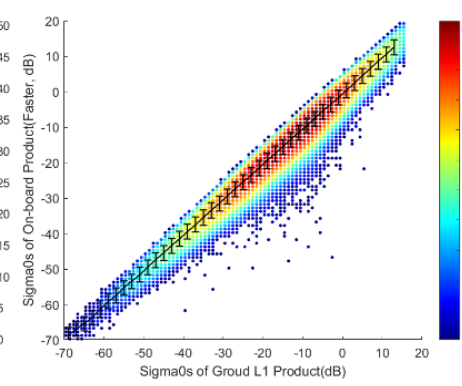

(b)

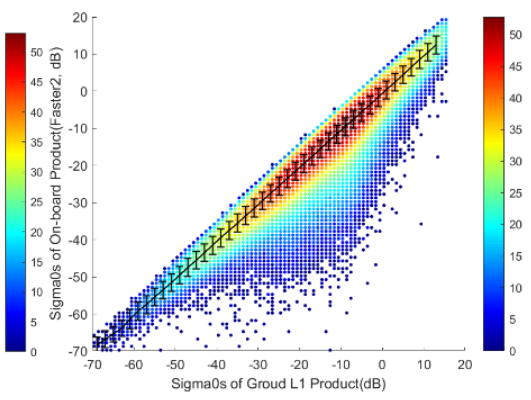

(c)

Figure 7. Correlation and error bars of NRCS for ground products (vertical axis) and on-board products (horizontal axis). Color indicates sample number density in dB. (a) illustrates results from LUTs in full resolution, and in in a half (b) and a quarter (c) number resampled LUTs. 
Table 2. Values from Figure 7.

\begin{tabular}{|c|c|c|c|c|c|c|}
\hline & \multicolumn{3}{|c|}{ Differences (dB) } & \multicolumn{3}{|c|}{ Stdev.(dB) } \\
\hline & Mean & Maximum & $\begin{array}{c}\text { Corresponding } \\
\text { Normalized Radar } \\
\text { Cross Section } \\
\text { (NRCS) of Maximum }\end{array}$ & Mean & Maximum & $\begin{array}{c}\text { Corresponding } \\
\text { NRCS of } \\
\text { Maximum }\end{array}$ \\
\hline $\begin{array}{l}\text { Look-Up Tabls (LUTs) } \\
\text { in original resolution }\end{array}$ & -0.28 & -0.53 & -63 & 1.83 & 1.94 & -61 \\
\hline $\begin{array}{l}\text { LUTs resampled in a } \\
\text { half number }\end{array}$ & -0.41 & -0.72 & -63 & 2.06 & 2.3 & -61 \\
\hline $\begin{array}{l}\text { LUTs resampled in a } \\
\text { quarter number }\end{array}$ & -0.52 & -0.82 & -63 & 2.2 & 2.57 & -61 \\
\hline
\end{tabular}

In Figure 7a, it can also be observed that the ground products and on-board NRCS had a good consistency. When on-board results were obtained in coarser LUTs, as shown in (b) and (c), more random noise was aroused. The biases of (b) and (c) to the eground products were similar to those from the on-board, full resolution LUTs. In Figure 7, due to the more random noise expressed in $\mathrm{dB}$, the regions in (b) and (c) with denser samples (deeper red) have a larger slope towards the negative direction of the vertical axis in (c) than (b), while in (a), such a feature is not shown. This is consistent with the conclusion that when the coarser LUTs were used, noisier products were obtained. Specific effects on wind products are provided later in this section. Figures 5-7 were derived from VV (transmitted and received in vertical polarization) observations. HH (transmitted and received in horizontal polarization) observations shared similar features and are not listed. For the wind inversion procedure, both polarized observations were applied with a resampled GMF LUT in both polarizations.

The wind inversion for CFOSCAT is based on the National Aeronautics and Space Administration Scatterometer GMF version 4 (NSCAT-4) [8]. The results are illustrated in Figures 8-11. Figure 8 shows the wind speed from the ground L2 products in (a), and the on-board wind inversion results were obtained in procedures described in Section 3. For (b) of Figure 8, resampled GMF LUTs in on-board inversion procedures were used for generating wind speeds. The horizontal axis is longitude, and the vertical axis is latitude. The resolution of the resampled GMF was of $0.4 \mathrm{~m} / \mathrm{s}$ in the wind speed dimension. The other dimensions were the same as those at full resolution, as the step length in the incidence angles is $0.1^{\circ}$, in the wind directions is $0.5^{\circ}$, and $0.1 \mathrm{~m} / \mathrm{s}$ in the wind speeds. The color in Figure 8 indicates wind speed amplitude in $\mathrm{m} / \mathrm{s}$. It can be observed that the wind speeds were of similar features for the three products. A randomly selected region from Figure 8 is shown in Figure 9. The horizontal and vertical axes, color bar, and products corresponding to (a), (b), and (c) are the same as those of Figure 8. The black arrows in Figure 9 indicate wind directions.

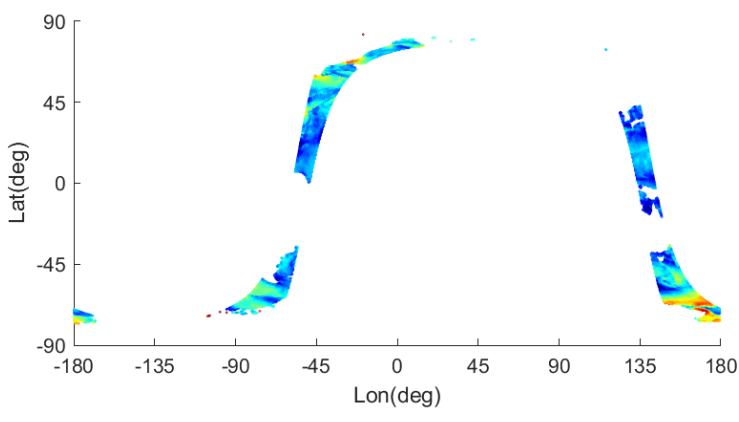

(a)

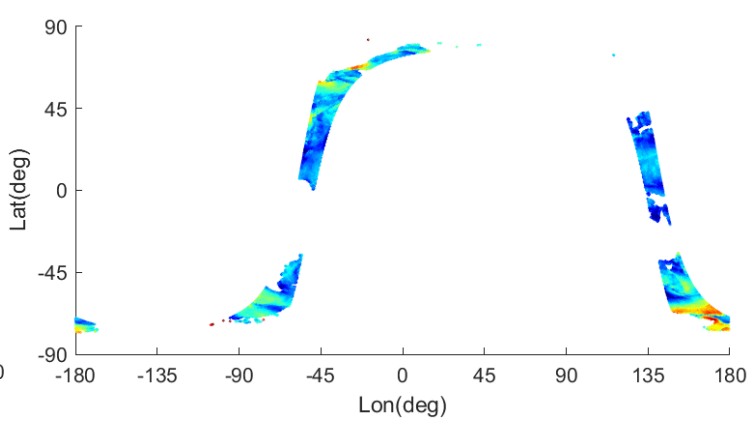

(b)

Figure 8. Cont. 


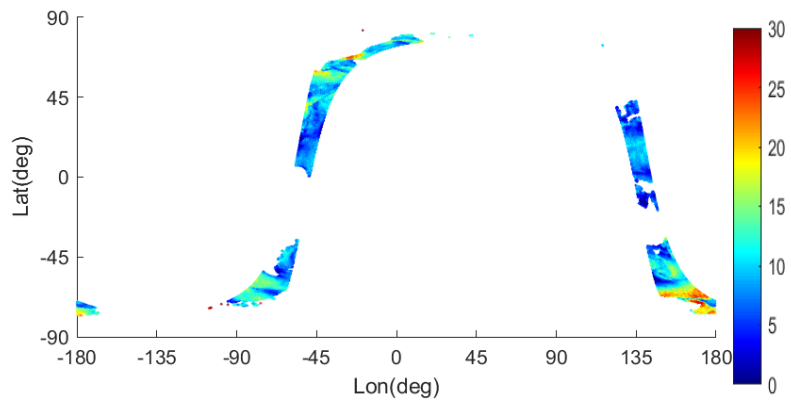

(c)

Figure 8. Wind speed of ground the L2 product (a) and that of on-board procedure in a full resolution geophysical modelling function (GMF) LUT (b) and a desampled GMF LUT (c). Color indicates wind speed in $\mathrm{m} / \mathrm{s}$.

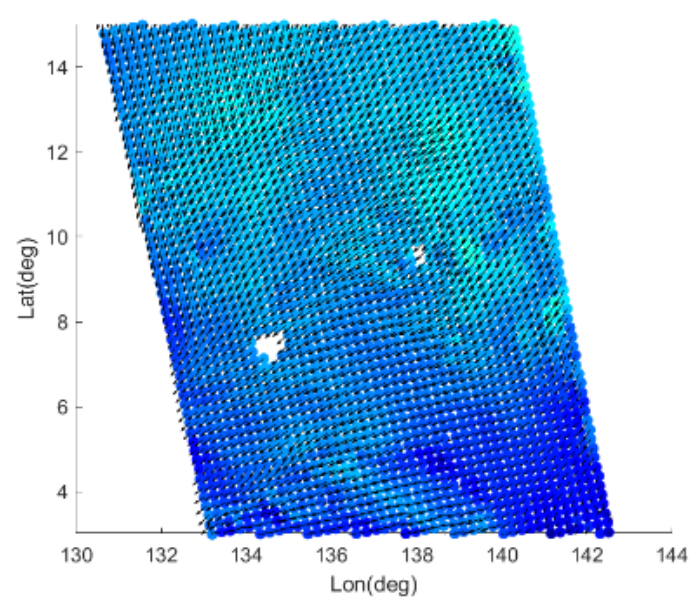

(a)

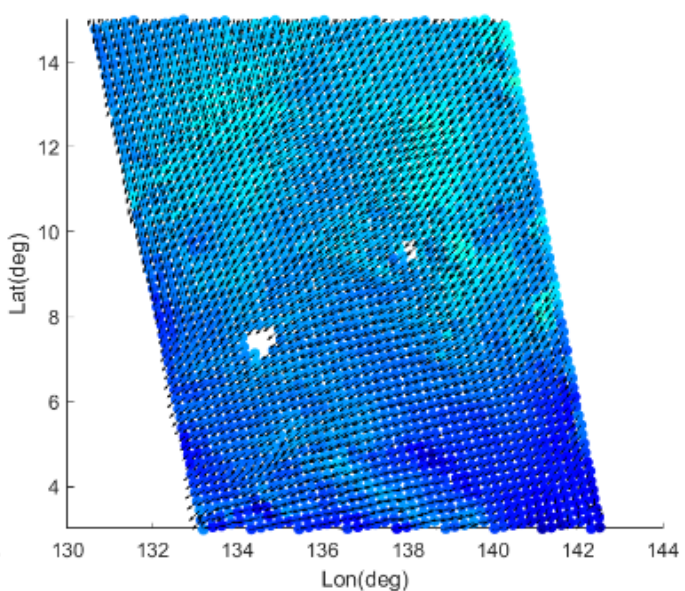

(b)

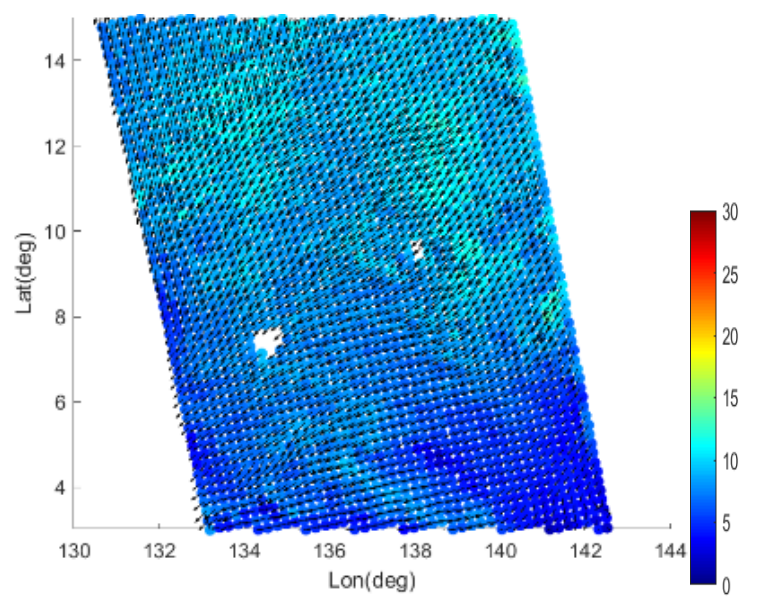

(c)

Figure 9. Wind speed of the ground L2 product (a) and that of the on-board procedure in a full resolution GMF LUT (b) and a desampled GMF LUT (c). Color indicates wind speed in m/s. 


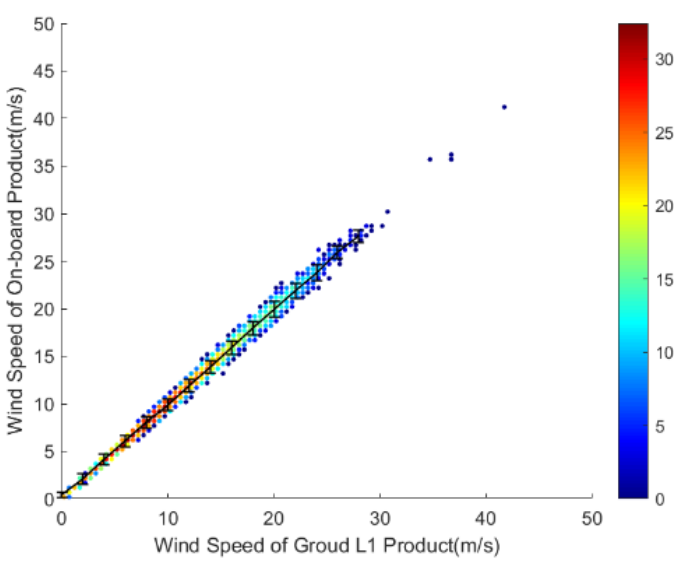

(a)

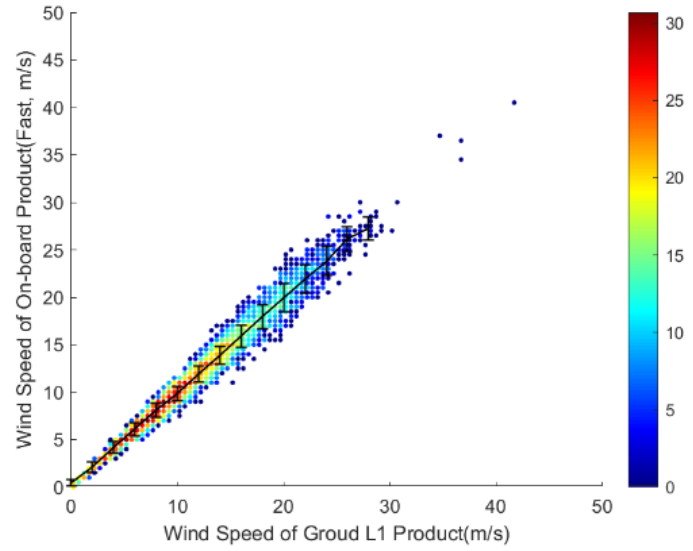

(b)

Figure 10. Correlation and error bars between the ground L2 product wind speed and the on-board wind speeds derived from a full GMF LUT (a) and a desampled GMF LUT (b). Color indicates wind speed in $\mathrm{m} / \mathrm{s}$.

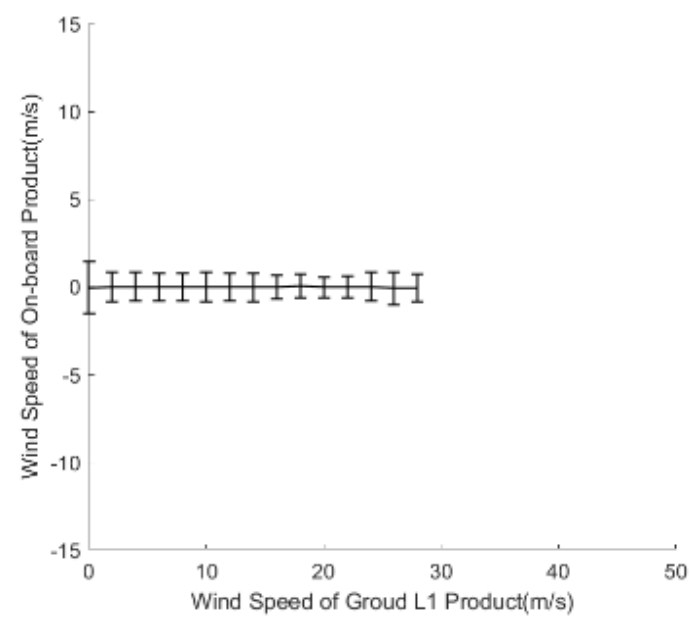

(a)

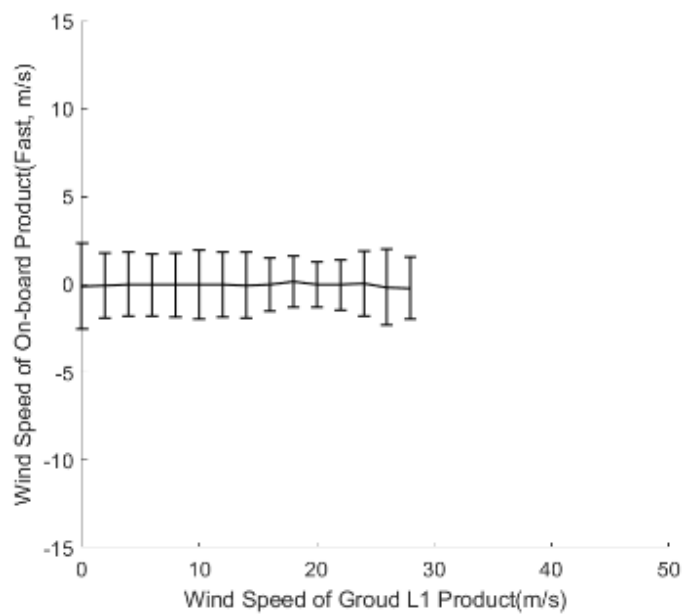

(b)

Figure 11. Mean differences and error bars of the ground L2 product wind direction and on-board wind directions derived from a full GMF LUT (a) and a desampled GMF LUT (b).

Figure 10 shows correlation and error bars between the ground L2 product wind speed and the on-board wind speeds, Figure 11 demonstrates the mean differences and error bars of the ground L2 product wind direction and on-board wind directions. Statistics came from the results of the whole dataset, as in Figure 8. Ground winds were used as references. The statistics of wind speed were obtained in a bin size of $2 \mathrm{~m} / \mathrm{s}$. Mean differences and stdev. in wind direction were calculated for different wind speed bins via the same procedure that was used for wind speed error analysis. In Figure 10, the horizontal axis represents the wind speeds from the ground L2 products, and the vertical axis represents the on-board wind speeds derived from a full-resolution GMF LUT (a) and that from a resampled GMF LUT (b). The mean absolute average differences of (a) and (b) are 0.14 and $0.17 \mathrm{~m} / \mathrm{s}$, respectively. The lowest and highest wind speed values were obtained from the $0 \mathrm{~m} / \mathrm{s}$ and $28 \mathrm{~m} / \mathrm{s}$ in wind speed, and these extreamly low and high speeds are of higher noise level in wind inversion and GMF themselves. For most wind speeds, (b) had slightly larger average differences than (a). The smallest average differences for both (a) and (b) were both at $18 \mathrm{~m} / \mathrm{s}$. The largest stdev. of (a) and (b) also appeared at $24 \mathrm{~m} / \mathrm{s}$ when mean differences were the largest at 0.84 and $1.55 \mathrm{~m} / \mathrm{s}$, respectively. The smallest stdev. values for (a) and (b) were all at $2 \mathrm{~m} / \mathrm{s}$ as 0.55 and $0.56 \mathrm{~m} / \mathrm{s}$, respectively. It can be 
observed from Figure 10 that (b) shows larger stdev. values than (a), indicating larger variance and more noise from the coarser GMF LUT. The better consistency observed in (a) also corresponded with the fact that, for ground wind inversion, interpolation was also employed to improve retrieval wind quality [39]. In Figure 11, it can be seen that the average differences in all wind speed bins for wind directions were close to $0^{\circ}$. However, there was an increase at $18 \mathrm{~m} / \mathrm{s}$ from $0.06^{\circ}$ to $0.15^{\circ}$ and at $26 \mathrm{~m} / \mathrm{s}$ from $-0.07^{\circ}$ to $-0.16^{\circ}$. These two bins also formed the second largest and largest average differences in wind direction. The trend of larger stdev. values for (b) than (a) is easy to see in Figure 11. The stdev. values are almost doubled in (b) taking reference from (a).

From Figures 5-11, it can be concluded that processing methods and LUTs proposed in this research for on-board processing can achieve good results for scatterometer wind compared with ground products. Better resolution LUTs for on-board processing are necessary for providing RT winds in good quality. To obtain a finer resolution of LUTs requires a longer processing time. The cost of calculation versus accuracy for on-board procedures is given in Figure 12, where the term standard represents full resolution LUTs applied in corresponding procedures. Simplified means that the half-number resampled LUTs, and more simplified indicates a quarter number of resampling in LUTs. The combination of different LUTs in pre-processing and inversion is expressed by different shapes. The solid curve is for wind speed, and the dashed curve represents wind direction. The RMSE value reached the minimum and time cost is the largest when using full resolution LUTs in both preprocessing and inversion. CFOSCAT takes up to 260 seconds (s) for obtaining this track of data. When excluding observation time, it generates $\mathrm{L} 0$ data at the speed of $1.3 \mathrm{~GB} / \mathrm{h}$ [43]. According to processing procedures described in Section 2, it can be found that the L1 and L2 products takes 0.8 and $0.06 \mathrm{~GB} / \mathrm{h}$ respectively. The observing duration for a track of data was $95 \mathrm{~min}$; under this on-board processing environment, data processing would cost around $165 \mathrm{~s}$ for a track. On average, this constitutes about a maximum of $2.95 \mathrm{~min}$ for observing a WVC in CFOSCAT. To complete adjacent WVCs for this kind of WVC, $5.9 \mathrm{~min}$ are required. Time is mainly consumed in the scatterometer observing procedure. For ground products involving ground stations for receiving, products are generally distributed in unit tracks. The on-board wind products are distributed based on the unit of a WVC with a much shorter product distribution duration. It can be concluded that full resolution LUTs can be applied for on-board wind inversion, while a comparable accuracy with ground products can be obtained in an on-board environment for RT applications.

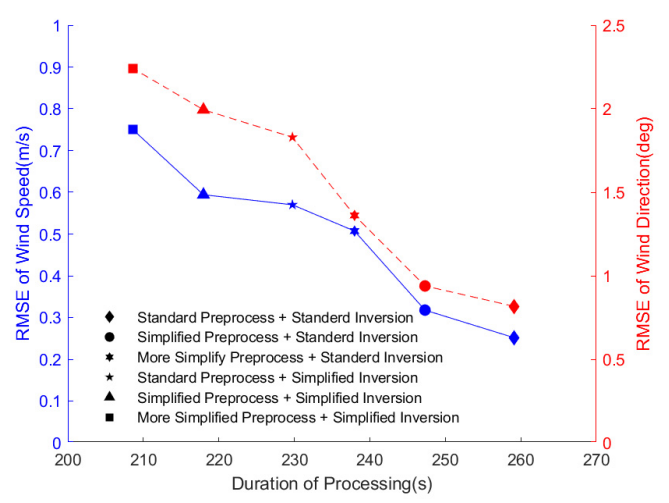

Figure 12. Cost of calculation vs. accuracy.

\section{Summary and Discussion}

In this research, an on-board wind scatterometry environment and data processing chain were established and tested in the simulation system. The simulation system was established by on-board processing modules and PCs. Data acquisition and distribution were simulated from PCs. In addition to traditional on-board data collection and processing steps, ground product generation procedures were realized on-board. Newly implemented modules were composed of a FPGA, DDR, and a 
GPU assembled into different motherboards. They can function for center control, I/O flow control, program execution, data swapping, and storage. Based on the setting of the on-board environment, modifications were made to the traditional scatterometer wind generation chain. Data packing flows were reduced before wind inversion, and LUTs were developed for accelerating calculation while avoiding iterations in the traditional chain. The results of experiments using CFOSCAT L0 data showed a comparable accuracy of on-board results taking reference from ground products in geolocation, NRCS derivationwith RMSE less than $0.93 \mathrm{~m},-0.53 \mathrm{~dB}$. The RMSE for wind speed is $0.17 \mathrm{~m} / \mathrm{s}$ and stdev. in wind direction is $-0.06^{\circ}$. An analysis of compromising accuracy for shorter processing time was achieved via simplifications of LUTs that had been established for the on-board processing chain. Results indicated that as LUTs are more simplified, random noise is more likely to be introduced and deteriorate accuracies. At the same time, decreases in time-consumption were not obvious. The most time-consuming procedure for the whole processing is at the observing step, which is dependent on scatterometer observation systems. The existing processing time, including observations was about $10.2 \mathrm{~min}$ for the most time-consuming WVC cases, which is much faster than existing ground processing chains. With next-generation satellite information transformation networks, the proposed on-board system and method can cover the global ocean's surface and make a good complement to existing satellite-observing-ground-processing-distributing chain for RT applications. Further research should explore the possibility of more complex wind direction ambiguity removal methods with NWP as background information, as well as the possibility of developing rain flags for processing in an on-board environment.

Author Contributions: X.X., X.D., and Y.X. conceived the main idea. X.X. and Y.X. performed the experiments. The manuscript was written by X.X., and it was improved by X.X., Xiaolong Dong and Y.X. All authors have read and agreed to the published version of the manuscript.

Funding: This work was supported by funds in part by the National Key Research and Development Program of China under Grant 2017YFB0502800 and 2017YFB0502802.

Acknowledgments: This work was supported by funds in part by the National Key Research and Development Program of China under Grant 2017YFB0502800 and 2017YFB0502802. The authors also want to thank the China National Space Administration (CNSA), Centre National d'Etudes Spatiales (CNES) for funding the CFOSAT project and the National Satellite Ocean Application Service (NSOAS) of China for providing data products.

Conflicts of Interest: The authors declare no conflict of interest.

\section{References}

1. Chang, P.S.; Jelenak, Z.; Sienkiewicz, J.; Knabb, R.; Brennan, M.; Long, D.G.; Freeberg, M. Operational Use and Impact of Satellite Remotely Sensed Ocean Surface Vector Winds in the Marine Warning and Forecasting Environment. Oceanography 2009, 22, 194-207. [CrossRef]

2. Stoffelen, A.; Kumar, R.; Zou, J.; Karaev, V.; Chang, P.S.; Rodriguez, E. Ocean Surface Vector Wind Observations. In Remote Sensing of the Asian Seas; Barale, V., Gade, M., Eds.; Springer: Cham, Switzerland, 2019; pp. $429-447$.

3. Benassai, G.; Migliaccio, M.; Montuori, A.; Ricchi, A. Wave Simulations Through Sar Cosmo-Skymed Wind Retrieval And Verification With Buoy Data. In Proceedings of the ISOPE-I-12-426, Rhodes, Greece, 17-22 June 2012; International Society of Offshore and Polar Engineers: Mountain View, CA, USA; p. 8.

4. Montuori, A.; Ricchi, A.; Benassai, G.; Migliaccio, M. Sea Wave Numerical Simulations and Verification in Tyrrhenian Coastal Area with X-Band Cosmo-Skymed SAR Data; European Space Agency, (Special Publication) ESA SP: Paris, France, 2011; Volume 703, p. 17.

5. Lin, C.-C.; Betto, M.; Rivas, M.B.; Stoffelen, A.; De Kloe, J. EPS-SG Windscatterometer Concept Tradeoffs and Wind Retrieval Performance Assessment. IEEE Trans. Geosci. Remote Sens. 2012, 50, 2458-2472. [CrossRef]

6. Stoffelen, A. Scatterometry. Ph.D. Thesis, Universiteit Utrecht, Utrecht, The Netherlands, 1996.

7. Stoffelen, A.; Verspeek, J.A.; Vogelzang, J.; Verhoef, A. The CMOD7 Geophysical Model Function for ASCAT and ERS Wind Retrievals. IEEE J. Sel. Top. Appl. Earth Obs. Remote Sens. 2017, 10,1-12. [CrossRef]

8. OSI SAF. Algorithm Theoretical Basis Document for the OSI SAF wind products and NSCAT-4 Geophysical Model Function. Available online: http://projects.knmi.nl/scatterometer/nscat_gmf/ (accessed on 22 July 2019). 
9. Verhoef, A.; Vogelzang, J.; Stoffelen, A. ASCAT L2 Winds Data Record Validation Report; Ocean and Sea Ice Satellite Application Facility, Eumetsat-Allee 1: Darmstadt, Germany; KNMI: De Bilt, The Netherlands, 2016.

10. Verhoef, A.; Stoffelen, A. ASCAT Wind Validation Report; Ocean and Sea Ice Satellite Application Facility; KNMI: De Bilt, The Netherlands, 2018.

11. Stoffelen, A.; Marseille, G. High Resolution Data Assimilation Guide; EUMETSAT: Darmstadt, Germany, 2018. Available online: https://www.nwpsaf.eu/site/download/documentation/scatterometer/reports/High_ Resolution_Data_Assimilation_Guide_1.2.pdf (accessed on 2 March 2020).

12. EUMETSAT. ASCAT_EUMETSAT. Available online: https://www.eumetsat.int/website/home/Satellites/ CurrentSatellites/Metop/MetopDesign/ASCAT/index.html/ (accessed on 2 March 2020).

13. AVISO. China France CFOSAT satellite data available. Available online: https://www.aviso.altimetry. fr/no_cache/en/news/front-page-news/news-detail.html?tx_ttnews\%5Btt_news\%5D=2533/ (accessed on 2 March 2020).

14. NSOAS. HY-2 Series: HY-2A \& HY-2B. Available online: http://www.nsoas.org.cn/eng/column/146.html (accessed on 2 March 2020).

15. eoPortal Directory. SCATSat-1-Satellite Missions. Available online: https://directory.eoportal.org/web/ eoportal/satellite-missions/s/scatsat-1 (accessed on 2 March 2020).

16. CEOS. Overview of Scatterometer Missions over Time (Years). Available online: http://ceos.org/ourwork/ virtual-constellations/osvw/ (accessed on 2 March 2020).

17. OSI SAF Winds Team. ScatSat-1 Wind Product User Manual Version 1.3; Ocean and Sea Ice Satellite Application Facility_Eumetsat-Allee 1: Darmstadt, Germany; KNMI: De Bilt, The Netherlands, 2018. Available online: http://projects.knmi.nl/scatterometer/publications/pdf/osisaf_cdop2_ss3_pum_scatsat1_winds.pdf. (accessed on 2 March 2020).

18. Stiles, B.; Pollard, B.; Dunbar, R. Direction interval retrieval with thresholded nudging: A method for improving the accuracy of QuikSCAT winds. IEEE Trans. Geosci. Remote Sens. 2002, 40, 79-89. [CrossRef]

19. Fore, A.; Stiles, B.W.; Chau, A.H.; Williams, B.A.; Dunbar, R.S.; Rodriguez, E. Point-Wise Wind Retrieval and Ambiguity Removal Improvements for the QuikSCAT Climatological Data Set. IEEE Trans. Geosci. Remote Sens. 2014, 52, 51-59. [CrossRef]

20. TD 14-EUMETSAT Advanced Retransmission Service Technical Description; EUMETSAT: Darmstadt, Germany, Eumetsat-Allee 1; 2019. Available online: https://www.eumetsat.int/website/wcm/idc/idcplg?IdcService= GET_FILE\&dDocName=PDF_DMT_112370\&RevisionSelectionMethod=LatestReleased\&Rendition=Web (accessed on 2 March 2020).

21. King, G.P.; Portabella, M.; Lin, W.; Stoffelen, A. Correlating Extremes in Wind and Stress Divergence with Extremes in Rain over the Tropical Atlantic; Ocean and Sea Ice SAF Scientific Report; KNMI: De Bilt, The Netherlands, 2017.

22. Gehrig, S.K.; Eberli, F.; Meyer, T. A Real-Time Low-Power Stereo Vision Engine Using Semi-Global Matching. In Computer Vision Systems; Academic Press: Cambridge, MA, USA, 2009; Volume 5815, pp. 134-143.

23. Qi, B.; Shi, H.; Zhuang, Y.; Chen, H.; Chen, L. On-Board, Real-Time Preprocessing System for Optical Remote-Sensing Imagery. Sensors 2018, 18, 1328. [CrossRef] [PubMed]

24. Wohlfeil, J.; Börner, A.; Buder, M.; Ernst, I.; Krutz, D.; Reulke, R. REAL TIME DATA PROCESSING FOR OPTICAL REMOTE SENSING PAYLOADS. In Proceedings of the XXII ISPRS Congress, Melbourne, Australia, 5 August-1 September 2012; Volume XXXIX-B5, pp. 64-68.

25. Lim, S.; Xiaofang, C. High performance on-board processing and storage for satellite remote sensing applications. In Proceedings of the 2014 IEEE International Conference on Aerospace Electronics and Remote Sensing Technology, Yogyakarta, Indonesia, 13-14 November 2014; pp. 137-141.

26. Yao, Y.; Jiang, Z.; Zhang, H.; Zhou, Y. On-Board Ship Detection in Micro-Nano Satellite Based on Deep Learning and COTS Component. Remote Sens. 2019, 11, 762. [CrossRef]

27. Foust, J. SpaceX's space-Internet woes: Despite technical glitches, the company plans to launch the first of nearly 12,000 satellites in 2019. IEEE Spectr. 2019, 56, 50-51. [CrossRef]

28. Xu, J.; Zhang, G. Design and Transmission Performance Analysis of Satellite Constellation for Broadband LEO Constellation Satellite Communication System Based On High Elevation Angle. IOP Conf. Ser.: Mater. Sci. Eng. 2018, 452, 042092. [CrossRef]

29. Zhou, G.; Baysal, O.; Kaye, J.; Habib, S.; Wang, C. Concept design of future intelligent Earth observing satellites. Int. J. Remote Sens. 2004, 25, 2667-2685. [CrossRef] 
30. Li, D.; Wang, M.; Dong, Z.; Shen, X.; Shi, L. Earth observation brain (EOB): An intelligent earth observation system. Geo-spatial Inf. Sci. 2017, 20, 134-140. [CrossRef]

31. Sevellec, F.; Drijfhout, S.S. A novel probabilistic forecast system predicting anomalously warm 2018-2022 reinforcing the long-term global warming trend. Nat. Commun. 2018, 9, 3024. [CrossRef] [PubMed]

32. Skolnik, M.I. Radar Handbook, 3rd ed.; McGraw-Hill Education: New York, NY, USA, 2008; pp. 18-53.

33. Woodhouse, I.H. Introduction to Microwave Remote Sensing; CRC Press: Boca Raton, FL, USA, 2005; p. 166.

34. Dunbar, S.; Stiles, B.; Huddleston, J.; Callahan, H.; Lungu, T.; Mears, C.; Wentz, F.; Smith, D. SeaWinds Science Data Product User's Manual Overview E Geophysical Data Products version 2; JPL: Pasadena, CA, USA, 2006. Available online: https://podaac-tools.jpl.nasa.gov/drive/files/allData/seawinds/L2BE/docs/SWS_SDPUG_V2. 0.pdf (accessed on 2 March 2020).

35. Nvidia, JETSON TX2. Available online: https://www.nvidia.cn/autonomous-machines/embedded-systems/ jetson-tx2 (accessed on 2 March 2020).

36. George, A.D.; Wilson, C.M. Onboard Processing With Hybrid and Reconfigurable Computing on Small Satellites. Proc. IEEE 2018, 106, 458-470. [CrossRef]

37. Su, Y.; Liu, Y.; Zhou, Y.; Yuan, J.; Cao, H.; Shi, J. Broadband LEO Satellite Communications: Architectures and Key Technologies. IEEE Wirel. Commun. 2019, 26, 55-61. [CrossRef]

38. Driesenaar, T.; de Kloe, J.; Stoffelen, A.; Forneris, V. PRODUCT USER MANUAL For Wind-Global Ocean L3 Wind; KNMI: De Bilt, The Netherlands, 2016. Available online: https:/cdn.knmi.nl/system/data_center_ publications/files/000/070/016/original/cmemsosipum012002.pdf?1495622122 (accessed on 2 March 2020).

39. Freilich, M.H. SeaWinds ALGORITHM THEORETICAL BASIS DOCUMENT; NASA: Washington, DC, USA, 2012. Available online: https://eospso.nasa.gov/sites/default/files/atbd/atbd-sws-01.pdf (accessed on 2 March 2020).

40. Spencer, M.W.; Wu, C.; Long, D.G. Improved resolution backscatter measurements with the SeaWinds pencil-beam scatterometer. IEEE Trans. Geosci. Remote Sens. 2000, 38, 89-104. [CrossRef]

41. Xu, X.; Dong, X.; Zhu, D.; Lin, W. Pre-processing algorithm and airborne campaign result analysis of a rotating fan-beam scatterometer. In Proceedings of the SPIE Asia-Pacific Remote Sensing, Beijing, China, 13-17 October 2014; SPIE: Bellingham, WA, USA; Volume 9264.

42. Vogelzang, J. Two Dimensional Variational Ambiguity Removal (2DVAR); KNMI: De Bilt, The Netherlands, 2017. Available online: http://citeseerx.ist.psu.edu/viewdoc/download;jsessionid= 88BBD01BAD28915EE1C4869F66E91F73?doi=10.1.1.627.1963\&rep=rep1\&type=pdf $\quad$ accessed on 2 March 2020).

43. Lin, W.; Dong, X.; Portabella, M.; Lang, S.; He, Y.; Yun, R.; Wang, Z.; Xu, X.; Zhu, D.; Liu, J. A Perspective on the Performance of the CFOSAT Rotating Fan-Beam Scatterometer. IEEE Trans. Geosci. Remote Sens. 2018, 57, 627-639. [CrossRef]

44. NSOAS. NSOAS Data Distribution. Available online: https://osdds.nsoas.org.cn (accessed on 22 January 2020). 